\title{
A New Approach for the Study of Chemical Mechanical Polishing
}

\author{
D. Devecchio, P. Schmutz, and G. S. Frankel*,z \\ Fontana Corrosion Center, Department of Materials Science and Engineering, The Ohio State University, Columbus, Ohio \\ 43210, USA
}

The process of chemical mechanical polishing (CMP) can be studied using in situ atomic force microscopy (AFM) by intentionally using a high tip/sample interaction force. The nominal removal rate of Al during AFM scratching is studied under a range of conditions including varying tip/sample force, solution $\mathrm{pH}$, and electrode potential. This approach should be useful for CMP process development and furthering the fundamental understanding of CMP mechanisms.

(C) 1999 The Electrochemical Society. S1099-0062(99)09-098-7. All rights reserved.

Manuscript submitted September 26, 1999; revised manuscript received November 4, 1999. Available electronically December 16, 1999.

The process of chemical mechanical polishing (CMP) of metal involves hard particles suspended in an aqueous slurry that interact with a metal surface because of mechanical force applied between the particles and surface by the polishing pad. ${ }^{1,2}$ The interaction may result in physical removal of metal or just breaking of a surface film, followed by electrochemical dissolution and reformation of a protective film. In order to understand better the mechanism of CMP, it is instructive to consider the process at its most basic level, i.e., a single abrasive particle being forced against the metal surface in the presence of an electrolyte. The premise of this paper is that this particle/metal interaction can be simulated by the interaction of an atomic force microscope (AFM) tip with a sample surface, thereby allowing a new approach to the study of the fundamental mechanisms of CMP.

Characterization of surface topography by AFM is typically performed under conditions that minimize the tip/sample interaction. However, in order to simulate CMP with the AFM, the opposite approach is followed. Instead of minimizing the tip/sample interaction, the tip is intentionally pushed against the sample surface with a higher tip force than usual. Guay et al. showed that the dissolution rate of pure aluminum thin films was locally enhanced during controlled AFM rastering in dilute chloride solutions. ${ }^{3,4}$ The loss of material was followed by determining the average roughness as a function of time. A relation between the applied force and the decrease of roughness was observed. ${ }^{4}$ Schmutz and Frankel used in situ AFM scratching of pure $\mathrm{Al}$ and an $\mathrm{Al}$ alloy in chloride solutions to study localized corrosion and repassivation processes. ${ }^{5}$ Under certain conditions, even in $0.5 \mathrm{M} \mathrm{NaCl}$, contact mode rastering of the AFM tip at a high force resulted in the formation of a deep, smoothbottomed trench in the pure $\mathrm{Al}$ surface. Clearly, the interactions between an AFM tip and the sample surface in an electrolyte can result in accelerated material removal.

The analogy of AFM scratching with metal CMP is as follows. An AFM cantilever, made of any of a number of materials ( $\mathrm{Si}$ and $\mathrm{Si}_{3} \mathrm{~N}_{4}$ cantilevers are readily available), is rastered across a metal sample in situ in contact mode using a high applied force. The metal sample is analogous to the metallized wafer in CMP, and metals such as Al, W, or $\mathrm{Cu}$ could be studied. The AFM tip with a contact diameter of about $50 \mathrm{~nm}$ pressing against the sample is analogous to the action of a single abrasive particle. The exact CMP slurry, but without particles, can be used in the AFM cell to simulate the environment. It is also possible to remove the oxidizing agent from the CMP slurry and use a potentiostat to control the sample potential, which provides an extra degree of freedom in designing a process. The force applied at the tip by the spring constant of the cantilever is analogous to the action of a polishing pad pushing an abrasive particle against the surface. The AFM allows much better control of the force than that achievable in a real CMP process. However, by accu-

\footnotetext{
* Electrochemical Society Active Member.

z E-mail: frankel.10@osu.edu
}

rately controlling the force, potential, and solution chemistry it is possible to use in situ contact mode AFM rastering to simulate and study CMP at its most basic level.

\section{Experimental}

A Digital Instruments Nanoscope IIIa AFM was used in these experiments. Bulk pure $\mathrm{Al}(99.99 \%)$ samples were polished to $6 \mu \mathrm{m}$ with diamond paste and then finished with colloidal silica to a final roughness of $2 \mathrm{~nm}$. They were studied in different environments, including sulfate and borate solutions with a range of $\mathrm{pH}$ levels. The solutions were pumped continuously at a rate of about $10 \mathrm{~mL} / \mathrm{h}$ through the electrochemical cell, which had a volume of about 0.1 $\mathrm{mL}$. The potential was either left at open circuit or controlled using a saturated mercurous sulfate electrode (MSE) and a Pt counter electrode located downstream of the cell. A square region of a given size, e.g., $5 \times 5 \mu \mathrm{m}$, was rastered with a Si tip for $1 \mathrm{~h}$ in contact mode at a specific applied force, as monitored by the setpoint voltage on the AFM photodiode. The scan region was then opened up, e.g., to $15 \mathrm{x}$ $15 \mu \mathrm{m}$, and the result of the high force scratching was imaged at low force. The nominal removal rate was determined as a function of setpoint voltage by measuring the depth of the trench created by the rastering and dividing by the raster time. This process was repeated sequentially with increasing setpoint voltage at nearby areas. The nominal removal rate of the scratched area determined in this fashion was referenced to the unscratched surface. It should be noted that under certain conditions the dissolution rate of the unscratched surface was relatively high.

\section{Results and Discussion}

An example of Al CMP produced by in situ AFM scratching is shown in Fig. 1. The central square region was rastered for $1 \mathrm{~h}$ in 0.5 $\mathrm{M} \mathrm{Na}_{2} \mathrm{SO}_{4}+0.01 \mathrm{M} \mathrm{Na}_{2} \mathrm{~B}_{4} \mathrm{O}_{7}(\mathrm{pH} 9.2)$ at open circuit (-1.7 to -1.9 $\mathrm{V}$ MSE) at a setpoint force of $3 \mathrm{~V}$. This resulted in the formation of a trench approximately $50 \mathrm{~nm}$ deep. The image shown in Fig. 1 was made in situ at a low setpoint force that itself did not result in any change in the surface as determined by AFM. A cross section of the smooth-bottomed trench formed by the rastering is shown in Fig. 1b. The trench is localized to the area that was rastered at the high set point and is quite different than the pitting that initiated during AFM scratching of $\mathrm{Al}$ in flowing chloride solutions. 5

Two observations help prove that the trench in Fig. 1 was created by a synergistic effect of the mechanical abrasion and the environment, i.e., CMP. The fact that a trench formed in the rastered area indicates that the region of the sample next to the rastered area dissolved at a much lower rate, and dissolution alone was not responsible for the trench. The trench was not formed by pure mechanical wear because a sample that was rastered in the exact same fashion as that in Fig. 1, except in air instead of in solution, exhibited no material removal (see Fig. 2). Note that the range for the gray scale values, representing the height of the topography, is only $20 \mathrm{~nm}$ for Fig. 2a compared to $200 \mathrm{~nm}$ for Fig. 1a. 
(a)

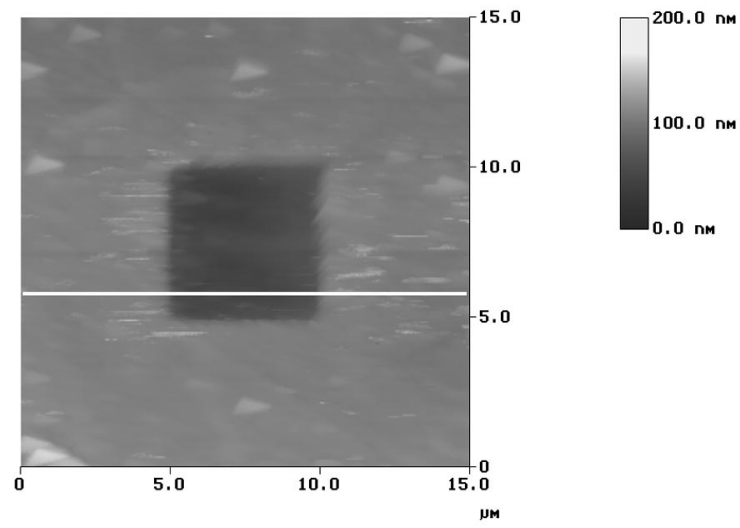

(b)

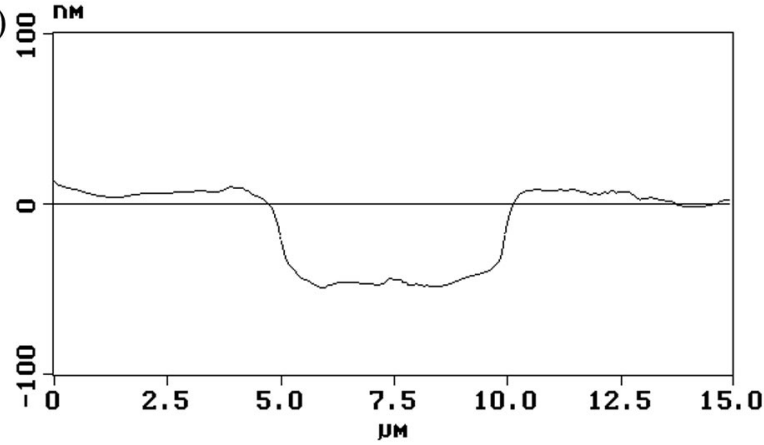

Figure 1. In situ contact mode AFM image of area of pure $\mathrm{Al}$ rastered for $1 \mathrm{~h}$ in $0.5 \mathrm{M} \mathrm{Na}_{2} \mathrm{SO}_{4}+0.01 \mathrm{M} \mathrm{Na}_{2} \mathrm{~B}_{4} \mathrm{O}_{7}(\mathrm{pH} 9.2)$ at open circuit (approximately $-1.9 \mathrm{~V}$ MSE) at a set point of $3 \mathrm{~V}$. (a) Expanded view of rastered area with $z$ range of $200 \mathrm{~nm}$ and (b) cross-sectional profile at location of line in part a.

The process of scratching at high loads causes the initially sharp but fragile Si tips to dull significantly with time. The triangles seen in Fig. 1a, which are images of the tip caused by small particles on the surface, are evidence of this dulling. The tip used to raster the sample shown in Fig. 2 was one that had been used previously in an in situ experiment that went to high setpoint voltages and was somewhat dulled as a result. Therefore, the effective pressure (force/tip-area) applied to the sample shown in Fig. 2 was similar to that in Fig. 1. It should be noted that it was possible to create a wear mark in $\mathrm{Al}$ in air by scratching with a fresh Si tip. For example, after scratching for $1 \mathrm{~h}$ in air with a new tip, a $4 \mathrm{~nm}$ deep wear mark was formed. Regardless of the exact tip condition, the material removal rates by scratching in the $\mathrm{pH} 9.2$ solution were much higher than those observed in air.

The nominal removal rate of $\mathrm{Al}$ during in situ AFM rastering in the $\mathrm{pH} 9.2$ borate/sulfate solution is shown in Fig. 3 as a function of applied potential and tip setpoint voltage, or force. It should be noted that the dissolution rate of the unscratched area was high in the $\mathrm{pH}$ 9.2 solution relative to the other solutions studied. As was found for AFM scratching of $\mathrm{Al}$ in stagnant $\mathrm{NaCl}$ solution, ${ }^{5}$ the material removal rate in the scratched area increased with increasing setpoint voltage, or higher tip/sample force. The rate also increased with increasing applied potential. The removal rate at about -1.4 V MSE was slightly higher than that at open circuit, which varied from -1.7 to $-1.9 \mathrm{~V}$ MSE during the time of the experiment. However, at a controlled potential of about $-0.9 \mathrm{~V}$, the removal rate increased by more than an order of magnitude.

The material removal rate was a sensitive function of $\mathrm{pH}$, which is expected based on the stability of $\mathrm{Al}$ oxide. The nominal removal rate during in situ AFM scratching of $\mathrm{Al}$ in $0.5 \mathrm{M} \mathrm{Na}_{2} \mathrm{SO}_{4}$ containing sufficient $\mathrm{H}_{2} \mathrm{SO}_{4}$ to form a $\mathrm{pH} 5$ was much lower than that in the pH 9.2 solution, Fig. 4. The removal rate in a $0.5 \mathrm{M} \mathrm{Na}_{2} \mathrm{SO}_{4}$ solu-

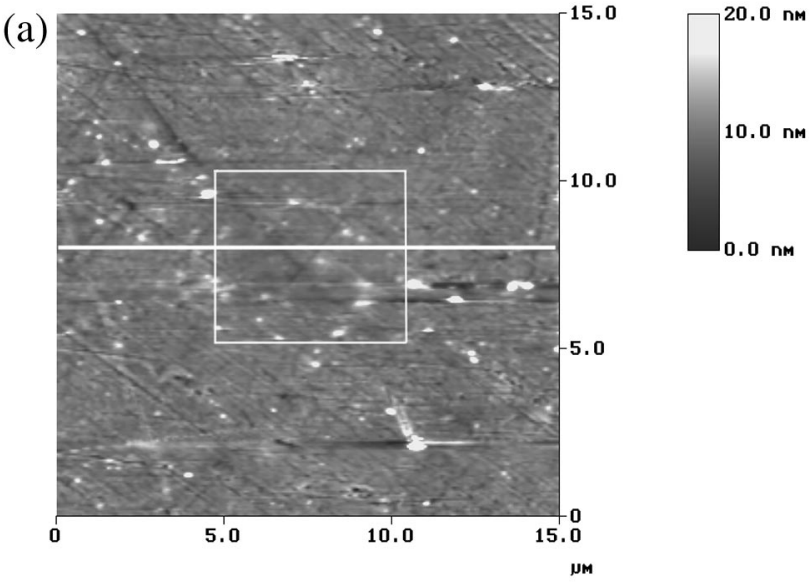

(b)

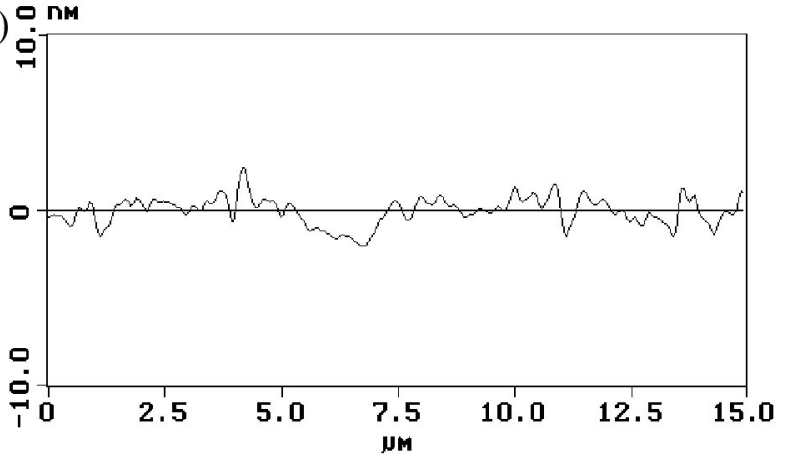

Figure 2. AFM image of area of pure $\mathrm{Al}$ rastered for $1 \mathrm{~h}$ in air at a set point of $3 \mathrm{~V}$. (a) Expanded view of rastered area with $z$ range of $20 \mathrm{~nm}$; the box indicates the location of the area rastered with the high set point, (b) crosssectional profile at location of line in part a.

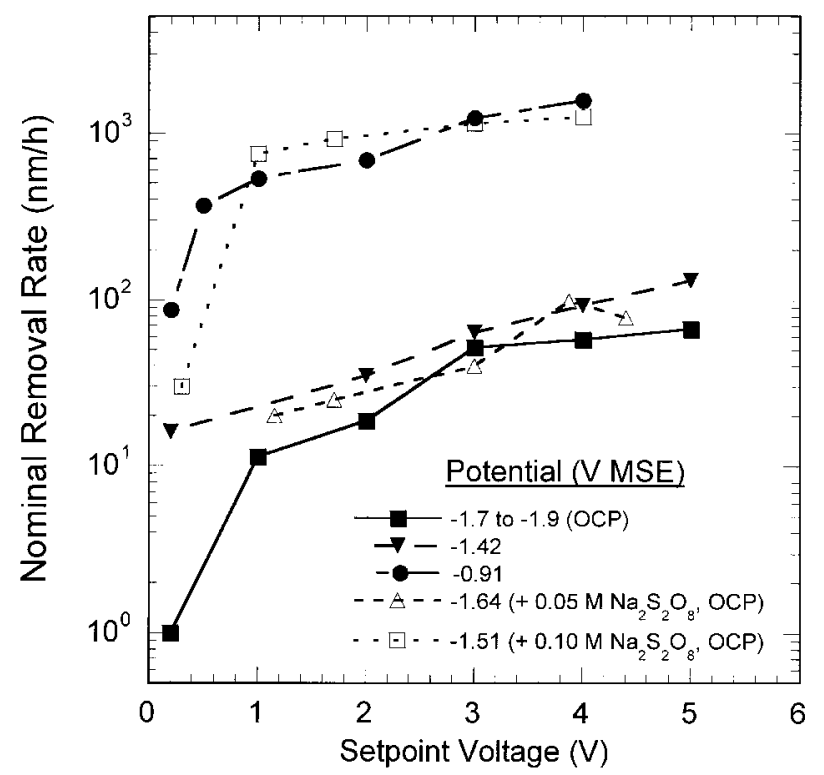

Figure 3. Nominal removal rate of pure $\mathrm{Al}$ during in situ $\mathrm{AFM}$ scratching in $0.5 \mathrm{M} \mathrm{Na}_{2} \mathrm{SO}_{4}+0.01 \mathrm{M} \mathrm{Na}_{2} \mathrm{~B}_{4} \mathrm{O}_{7}(\mathrm{pH} 9.2)$ as a function of setpoint voltage on the AFM photodiode. Measurements at the open-circuit potential (OCP) and two applied potentials are shown. Also shown is the removal rate at open circuit in solutions containing $\mathrm{Na}_{2} \mathrm{~S}_{2} \mathrm{O}_{8}$. 


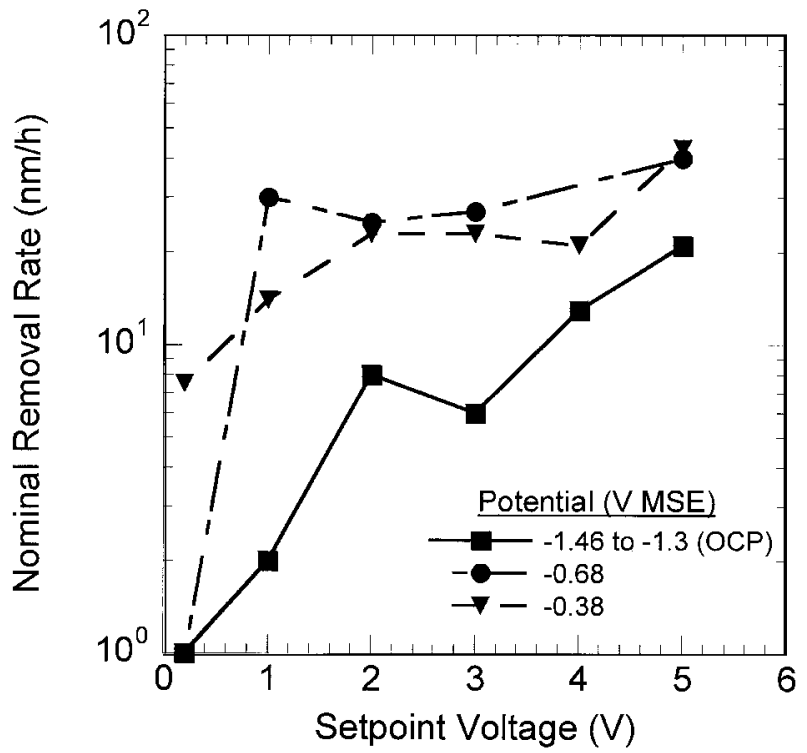

Figure 4. Nominal removal rate of pure $\mathrm{Al}$ during in situ AFM scratching in $0.5 \mathrm{M} \mathrm{Na}_{2} \mathrm{SO}_{4}+0.0001 \mathrm{M} \mathrm{H}_{2} \mathrm{SO}_{4}(\mathrm{pH} 5)$ as a function of setpoint voltage on the AFM photodiode and electrode potential.

tion buffered at $\mathrm{pH} 7$ (by adding $0.09 \mathrm{M} \mathrm{H}_{3} \mathrm{BO}_{3}$ and $0.0005 \mathrm{M}$ $\mathrm{Na}_{2} \mathrm{~B}_{4} \mathrm{O}_{7}$ ) was almost identical to that in the $\mathrm{pH} 5$ solution. Applied potential had an accelerating influence in the $\mathrm{pH} 5$ and $\mathrm{pH} 7$ solutions, but much less than for the $\mathrm{pH} 9.2$ solution. The higher potential drives dissolution, but also anodization, which would tend to make a more robust film.

CMP slurries typically contain an oxidizing agent to accelerate the dissolution. The in situ AFM scratching approach can be used with the potential increased by the presence of an oxidizing agent instead of using an applied anodic potential. The results of scratching $\mathrm{Al}$ in $0.5 \mathrm{M} \mathrm{Na}_{2} \mathrm{SO}_{4}+0.01 \mathrm{M} \mathrm{Na}_{2} \mathrm{~B}_{4} \mathrm{O}_{7}$ containing $0.05 \mathrm{M}$ or $0.1 \mathrm{M} \mathrm{Na}_{2} \mathrm{~S}_{2} \mathrm{O}_{8}$ are shown in Fig. 3. The $\mathrm{pH}$ decreased slightly as a result of the addition of persulfate; it was 9.1 and 9.0 for solutions containing 0.05 and $0.1 \mathrm{M}$ persulfate, respectively. The open circuit potentials for $\mathrm{Al}$ in these solutions were -1.64 and -1.51 V MSE, respectively. Note that the nominal removal rate at the open circuit potential of $-1.51 \mathrm{~V}$ in the presence of $0.1 \mathrm{M}$ persulfate was much higher than at a controlled potential of $-1.42 \mathrm{~V}$ in the absence of persulfate, and equivalent to that at $-0.91 \mathrm{~V}$ in the absence of persulfate. In other words, to achieve a removal rate measured under open circuit conditions in the presence of an oxidizing agent, it was necessary to use a much higher applied potential.

When an anodic potential is applied by a potentiostat, the cathodic reaction is primarily located at the remote counter electrode. In contrast, when the potential is achieved by the presence of an oxidizing agent, the cathodic reaction occurs in close proximity to the anodic reaction. The scratched area is a very small fraction of the total exposed area, suggesting that the cathodic reaction could occur at a relatively distant location on the same electrode. However, the reactivity of the fresh $\mathrm{Al}$ surface is much greater than that of the nearby passive surface, as evidenced by the copious hydrogen evolution observed in pits in Al. Therefore, it is likely that a large fraction of the cathodic reaction occurs very close to the scratching tip. The borate in the solution makes it rather well buffered, and the reduction of persulfate to sulfate should not affect the $\mathrm{pH}$

$$
\mathrm{S}_{2} \mathrm{O}_{8}^{2-}+2 \mathrm{e}^{-} \rightarrow 2 \mathrm{SO}_{4}^{2-}
$$

However, small changes in $\mathrm{pH}$ are likely as a result of the cathodic reaction. Dissolved oxygen is present even in the presence of persulfate, and oxygen reduction will also take place, which would tend to increase the $\mathrm{pH}$ locally. Furthermore, the addition of persulfate to the sulfate/borate solution decreased the $\mathrm{pH}$ slightly, so the consumption of persulfate by Reaction 1 would result in a local increase in $\mathrm{pH}$. The $\mathrm{pH}$ of 9-9.2 is in the range where the stability of $\mathrm{Al}_{2} \mathrm{O}_{3}$ is a sensitive function of $\mathrm{pH}$. So it is possible that the higher rate of material removal at open circuit in the presence of an oxidizing agent relative to that at a similar applied potential was a result of small local $\mathrm{pH}$ increases associated with the cathodic reaction.

The nominal removal rates shown in Fig. 3 and 4 should scale with the CMP rate, but should not be compared directly. The tip was in contact with a given spot on the rastered area only a small fraction the total raster time. The nominal removal rate was limited by this contact time. The correlation to CMP must account for the average number of contact points per unit area between the abrasive particles and the substrate at any given time.

\section{Conclusions}

It has been shown that in situ AFM scratching of pure $\mathrm{Al}$ can result in accelerated removal of material within the rastered area by a process similar to CMP. The removal rate depended strongly on solution $\mathrm{pH}$, electrode potential, and the applied tip/sample force, as indicated by the AFM setpoint voltage. It is suggested that this approach will be useful for clarifying the mechanisms of CMP and for rapidly screening CMP solutions during process development.

\section{Acknowledgment}

This work was supported by the United States Air Force Office of Scientific Research under the direction of Major Paul Trulove through grant no. F49620-96-1-0479.

The Ohio State University assisted in meeting the publication costs of this article.

\section{References}

1. F. B. Kaufman, D. B. Thompson, R. E. Broadie, M. A. Jaso, W. L. Guthrie, D. J. Pearson, and M. B. Small, J. Electrochem. Soc., 138, 3460 (1991).

2. J. M. Steigerwald, S. P. Murarka, and R. J. Gutmann, Chemical Mechanical Planarization of Microelectronic Materials, John Wiley \& Sons, Inc., New York (1997).

3. L. Chen and D. Guay, J. Electrochem. Soc., 141, L43 (1994).

4. L. Roue, L. Chen, and D. Guay, Langmuir, 12, 5818 (1996).

5. P. Schmutz and G. S. Frankel, J. Electrochem. Soc., 145, 2295 (1998). 